\title{
PROPAGACIÓN DE PLANTAS CHILENAS EN RIESGO DE EXTINCIÓN PARA SU CONSERVACIÓN $e x$ situ EN BANCO DE SEMILLAS
}

\section{PROPAGATION OF CHILEAN PLANTS WITH EXTINCTION RISKS FOR ITS $e x$ situ COSERVATION IN A SEED BANK}

\author{
Sandoval, A. ${ }^{1}$ y P. León-Lobos ${ }^{1,2}$. \\ 'Banco Base de Semillas, Instituto de Investigaciones Agropecuarias (INIA), Casilla 73, \\ Vicuña, Chile. E-mail: anasandoval@tie.cl \\ ${ }^{2}$ Centro de Estudios Avanzados en Zonas Áridas (CEAZA), La Serena, Chile.
}

\section{INTRODUCCIÓN}

La gran diversidad de plantas presentes únicamente en nuestro país, así como el valor ornamental de muchas de ellas otorga importancia mundial a nuestra flora. La zona central de Chile concentra la mayoría de esta diversidad, pero como también concentra la actividad humana, la amenaza a tales recursos es constante, poniendo en peligro la conservación de muchas de estas especies. Por estos motivos, esta zona es considerada como uno de los sitios prioritarios para la conservación global (Myers et al. 2000). La conservación ex situ, en bancos de semillas y en jardines botánicos, surge como una clara necesidad para la conservación a largo plazo de las especies en riesgo de extinción. Sin embargo, las escasas poblaciones existentes de varias especies amenazas, no producen suficientes cantidades de semillas para que la conservación en bancos de semillas sea efectiva. Por ello, su propagación, con el fin de incrementar la cantidad de semillas disponibles para su conservación a largo plazo, surge como una necesidad para asegurar la preservación de la integridad y diversidad genética de las poblaciones, así como su disponibilidad futura.

\section{MATERIAL Y MÉTODO}

El Banco Base de Semillas, INIA, desarrolla actividades de propagación para los fines descritos. Se está trabajando con al menos 14 especies que habitan zonas semiáridas de Chile. Cinco de ellas se han considerado prioritarias debido a alto grado de amenaza en que se encuentran. Dalea azurea, una leguminosa endémica de la II región y que se encuentra en peligro de extinción, con no mas de dos poblaciones conocidas. Tigridia philippiana (Iridaceae), también endémica de la II región, es considerada rara. Ambas especies habitan en el borde costero en la zona de Paposo. Placea lutea (Amaryllidaceae), endémica de la $\mathrm{V}$ región, de distribución muy restringida, amenazada por el pastoreo. Adesmia resinosa, endémica de las regiones $\mathrm{V}$ y Metropolitana, Adesmia balsamica, endémica de la $\mathrm{V}$ región, ambas leguminosas consideradas raras.

\section{RESULTADOS Y CONCLUSIÓN}

La colecta de semillas realizada en las escasas poblaciones naturales, considera estrategias de muestreo que permiten capturar su diversidad genética, sin afectar su capacidad de regeneración (Gold et al. 2004). Gran parte de estas especies están siendo propagadas por semillas (Cuadro 1), aunque en algunos casos se ha realizado además propagación vegetativa, utilizando bulbos o estacas. La sobrevivencia de las plántulas ha sido exitosa, aunque los bajos niveles de germinación en algunas de estas especies han motivado la realización de nuevos ensayos que permitan mejorar la tasa de germinación de las semillas y por ende el aprovechamiento de las mismas. Una vez que, las plantas alcancen su etapa reproductiva se realizaran estudios sobre su biología reproductiva y cruzamientos controlados para producción de semillas y su posterior conservación en el largo plazo en el banco de semillas. 
Cuadro 1. Especies propagadas en invernadero, su estado de conservación y resultados parciales de propagación, por semillas y en forma vegetativa.*

Table 1. Greenhouse propagated species, their state of conservation and partial results of vegetative and seed propagation.

\begin{tabular}{|c|c|c|c|}
\hline & $\begin{array}{c}\text { Estado de } \\
\text { Conservación }\end{array}$ & $\begin{array}{c}\text { Germinación } \\
(\%)\end{array}$ & $\begin{array}{c}\text { Brotación } \\
(\%)\end{array}$ \\
\hline \multicolumn{4}{|l|}{ Alliaceae } \\
\hline Gethyum cuspidatum & Vulnerable & 3,0 & 21,7 \\
\hline $\begin{array}{l}\text { Leucocoryne purpurea } \\
\text { Iridaceae }\end{array}$ & Vulnerable & & 90,9 \\
\hline Tigridia philipiana & Rara & 12,0 & \\
\hline \multicolumn{4}{|l|}{ Amaryllidaceae } \\
\hline Placea amoena & Vulnerable & $98,0^{*}$ & 64,3 \\
\hline Placea arzae & Vulnerable & $98,7^{*}$ & 80,0 \\
\hline Placea davidii & Rara & $84,7^{\star}$ & 100 \\
\hline Placea aff. germanii & Rara & & 90,9 \\
\hline Placea grandiflora & No evaluada & $88,7^{*}$ & 100 \\
\hline Placea lutea & No evaluada & $81,9^{*}$ & 100 \\
\hline Placea ornata & Rara & $95,2^{*}$ & 100 \\
\hline $\begin{array}{l}\text { Placea sp. } \\
\text { Papilionaceae }\end{array}$ & No evaluada & 64,0 & 97,4 \\
\hline Adesmia resinosa & Rara & 29,4 & \\
\hline Adesmia balsamica & Rara & 4,3 & \\
\hline Dalea azurea & En Peligro & 91,7 & 91,6 \\
\hline
\end{tabular}

\section{BIBLIOGRAFÍA}

GOLD, K.; LEÓN-LOBOS, P.; WAY. M. 2004. Manual de recolección de semillas de plantas silvestres para conservación a largo plazo y restauración ecológica. Instituto de Investigaciones Agropecua- rias, Centro Regional de Investigación Intihuasi, La Serena, Chile. Boletín INIA No $110,62 \mathrm{p}$. MYERS, N.; MITTERMEIER, R.A.; MITTERMEIER, C.G.; FONSECA, G.; KENT. J. 2000. Biodiversity Hotspot for conservation priorities. Nature 403: 853-858.

\section{EVALUACIÓN DE PLANTAS NATIVAS PARA DECORAR NUESTROS JARDÍNES}

\section{EVALUATION OF NATIVE PLANTS FOR EMBELLISHING OUR GARDENS}

Barrionuevo, V., Planchuelo, A.M y Fuentes, E.

Facultad de Ciencias Agropecuarias. Universidad Nacional de Córdoba, Argentina. Avda. Valparaíso s./n C.C. 509 - 5000 Córdoba-Argentina.

E-mail: vbbarrionuevo@yahoo.com.ar

\section{INTRODUCCIÓN}

La cobertura vegetal de la provincia de Córdoba es muy heterogénea, presentando unidades de vegetación que se encuentran muy degradadas (Cabido y Zac, 1999). Numerosas áreas de las sierras chicas han experimentado una gran pérdida de vegetación natural y de germoplasma 